\title{
Improving organizational learning through leadership training
}

\author{
Henna Hasson
}

Procome research group, Medical Management Centre (MMC), Department of Learning, Informatics, Management and Ethics, Karolinska Institutet, Stockholm, Sweden and Centre for Epidemiology and Community Medicine, Stockholm County Council, Stockholm, Sweden

\section{Ulrica von Thiele Schwartz}

Procome research group, Medical Management Centre (MMC), Department of Learning, Informatics, Management and Ethics, Karolinska Institutet, Stockholm, Sweden

\section{Stefan Holmström}

Department of Psychology, Umeå University, Umeå, Sweden

Maria Karanika-Murray

College of Business Law \& Social Sciences, School of Social Sciences, Nottingham Trent University, Nottingham, UK

Susanne Tafvelin

Procome research group, Medical Management Centre (MMC), Department of Learning, Informatics, Management and Ethics, Karolinska Institutet, Stockholm, Sweden and Department of Psychology, Umeå University

Corresponding author: Hasson Henna, E-mail: henna.hasson@ki.se

Published as: HASSON, H., VON THIELE SCHWARZ, U., HOLMSTROM, S., KARANIKA-MURRAY, M., TAFVELIN, S., 2016. Improving organizational learning through leadership training. Journal of Workplace Learning, 28 (3), pp. 115-129. 


\title{
Improving organizational learning through leadership training
}

\begin{abstract}
Purpose: Managers play a crucial role in providing opportunities to employees for learning. Although scholars have called for intervention research on the effects of leadership development on organizational learning, no such research is currently available. This paper evaluates whether training of managers at workplaces can improve organizational learning. Methodology: The training program consisted of theoretical and practical elements aimed to improve line managers' transformational leadership behaviors and, in turn, improve organizational learning. The study used a pre- and post-intervention evaluation survey. Line managers' and their subordinates' perceptions of organizational learning were measured with the Dimensions of Organizational Learning Questionnaire and with post-intervention single items on organizational learning.
\end{abstract}

Findings: Comparisons between pre-and post-intervention assessments revealed that managers' ratings of Continuous Learning and employees' ratings of Empowerment and Embedded Systems improved significantly as a result of the training. The leadership training intervention had positive effects on managers' perceptions of individual-level and on employees' perceptions of organizational-level aspects of organizational learning.

Originality/value: The study provides empirical evidence that organizational learning can be improved through leadership training. Both line managers and their subordinates perceived that organizational learning had increased after the training intervention, albeit in different ways. Implications for developing leadership training programs and for evaluating these are discussed.

Keywords: Leadership training; organizational learning, intervention study, transformational leadership, line managers 


\section{Improving organizational learning through leadership training}

Organizational learning is a well-documented determinant of desirable organizational outcomes such as financial performance, innovation capacity, and customer value (Yukl, 2009, Davis and Daley, 2008, Ellinger et al., 2002, Ellinger et al., 2003, García-Morales et al., 2012, Jiménez-Jiménez and Sanz-Valle, 2011, Baker and Sinkula, 2002, Valencia et al., 2010, Santos-Vijande et al., 2012). The rationale for attempting to improve these outcomes via improving organizational learning is that the subsequent development of new knowledge can reduce the likelihood that a company's human capital will become outdated, thus enabling the skills and knowledge to remain dynamic, and improving organizational performance (GarcíaMorales et al., 2012).

\section{Organizational Learning}

Organizational learning is often defined as a change in the organization's knowledge that occurs as a function of experience (Argote, 2011). This knowledge can manifest itself in changes in cognitions, routines, and behaviors (Argote, 2011). Thus, organizational learning is a process that involves continuous change in individuals' cognitions and behaviors (Argote, 2011). Individual employees are the mechanisms through which organizational learning takes place as individual learning processes become embedded in organizational functions (Argote, 2011, Nonaka and Takeuchi, 1995). Learning and knowledge generated by individuals cannot be sustained in an organization unless they are supported by actions. To develop sustained learning, ideas need to be shared, actions taken, and common meaning developed (Argyris and Schon, 1996, Huber, 1991). Thus, organizational learning takes place via the social processes and group dynamics that govern individuals' interactions (Crossan et al., 1999). 
Scholars have suggested that organizational learning occurs at three levels: the individual, the group, and the organization (Crossan et al., 1995, Crossan et al., 1999, Marsick and Watkins, 2003). Correspondingly, seven distinct but interrelated dimensions of a learning organization have been proposed (Marsick and Watkins, 2003, Yang, 2003, Yang et al., 2004). The individual level is composed of two dimensions: Continuous Learning represents an organization's effort to create learning opportunities for all of its members. Dialogue and inquiry refers to an organization's effort to create a culture of questioning, feedback, and experimentation. These two dimensions represent learning at the individual level. Team Learning is reflected in work processes related to teams' goal setting, information sharing and collaboration, and reflects the organization's efforts in relation to these aspects. Embedded systems indicates efforts to establish systems to capture and share learning. System connections reflects the connection between the internal and external environments. Empowerment signifies an organization's process to create and share a collective vision, and use feedback from its members on the gap between the current status and the new vision. Providing leadership for learning deals with leaders' strategic thinking about how to use learning to create change and to move the organization in new directions. These four latter dimensions represent organizational-level learning. The development of organizational learning requires strength in all these aspects (Marsick and Watkins, 2003, Yang, 2003, Yang et al., 2004).

\section{Leadership and Organizational Learning}

Leadership is one of the most important organizational function that influences the conditions for collective learning (Yukl, 2009, Aragon-Correa et al., 2007, García-Morales et al., 2012, Vera and Crossan, 2004, Berson et al., 2006, Gomez and Ranft, 2003, Beattie, 2006), as it constitutes a process of facilitating individual and collective efforts to learn and accomplish 
shared goals in the organization (Berson et al., 2006). This influence has been suggested to be both direct and indirect, through leaders' direct actions and communication with employees, or though their role in creating favorable conditions for learning and implementing appropriate supporting activities and structures, respectively (Yukl, 2009, Yukl and Lepsinger, 2004). In support of this, research has illuminated potential mechanisms by which leadership can impact organizational learning. Specifically, Berson et al. (2006) argue that there are three mechanisms for this: the provision of contextual support and bolstering resources, the provision of guidance on how to integrate learning across work groups, and the institutionalization of learning into the organization's practices and policies. Furthermore, there is evidence that leaders can increase employees' developmental readiness, or ability and motivation for learning, by influencing the function and structure of learning networks, and by actively helping to diffuse and institutionalize learning and new knowledge (Hannah and Lester, 2009).

A large volume of research on leadership and organizational learning has focused on the value of transformational leadership (Vera and Crossan, 2004, Yukl, 2009). Transformational leadership is a vision-based approach to leadership that builds on the importance of a strong identification with the leader and the work unit where the leadership takes place (Bass and Riggio, 2006). The leader acts as a role model who inspires and motivates employees to perform beyond expectations and encourages them to go beyond their own personal goals and interests for the collective good (Bass and Riggio, 2006, Bass, 1999). The concept of transformational leadership is composed of four dimensions (Bass, 1985): idealized influence (the leader acts as a role model and gains trust and respect of his or her followers), inspirational motivation (the leader formulates a clear and attractive vision and hold high expectations that followers will achieve more than they thought possible and ultimately reach 
the vision), intellectual stimulation (the leader encourages followers to make their own decisions, to find new ways of working, and to be creative and innovative), and individualized consideration (the leader spends time coaching followers and provides personal attention to their development and achievements).

Transformational leadership has shown to be significantly related to both structural (organizational learning mechanism) and cultural (organizational learning values) learning components (Amitay et al., 2005). It has also been demonstrated that transformational leadership can influence organizational learning by promoting intellectual stimulation and providing inspirational motivation and self-confidence among employees (Coad and Berry, 1998). It can also generate greater awareness and acceptance of the organizational goals and foster a shared vision, and re-orientate learning activities and the construction of work teams. Transformational leadership can also allow leaders to commit to learning and provide what is needed to overcome internal skepticism and external difficulties to establish learning within the organization (Wick and León, 1995). In addition, an indirect effect of transformational leadership on organizational learning has been suggested via the leaders' influence on communication (Argyris and Schon, 1996, Schein, 2004). These studies offer important suggestions on how leaders influence learning at the individual, team, and organization levels (Yukl, 2009). However, the available research offers little guidance on improving leadership capacity to enable and promote organizational learning.

There is also a substantial body of research that indicates the positive impact of leadership training across a wide variety of settings, industries, and outcomes, regardless of the theoretical perspective adopted by the researchers (Avolio et al., 2009). Most studies have focused on transformational leadership training, demonstrating that such training can increase 
not only employees perception of leaders' transformational leadership (Barling et al., 1996, Kelloway et al., 2000, Duygulu and Kublay, 2011, Brown and May, 2012, Fitzgerald and Schutte, 2010) but also their attitudes and behaviors. For example, Hardy et al. (2010) found that transformational leadership training in the British army increased employees' selfconfidence and resilience. Dvir et al. (2002) demonstrated a positive impact of transformational leadership training in the Israeli army on follower self-efficacy, extra effort, critical-independent approach, and objective performance. Barling et al. (1996), in a sample of Canadian bank employees, found significant improvements in commitment and performance among followers whose leaders had attended a transformational leadership training program.

Despite this evidence, and calls from scholars for intervention studies on the effects of leadership and training on organizational learning (Yukl, 2009), to the best of our knowledge no such studies are available or have been published to date. Thus, it remains unclear whether training workplace leaders can improve learning in an organization. Therefore, this study examined the possible impact of a training intervention for line managers on their and employees' ratings of organizational learning. The following research question was investigated:

Can a training program consisting of theoretical and practical elements to increase transformational leadership behaviors improve managers' and employees' ratings of learning at the individual, group and organization levels?

This study offers two needed contributions to the literature. First, it adds to the current knowledge on leadership training by evaluating whether a training program developed for line managers can impact on organizational learning. Second, it expands the literature through the 
evaluation of two stakeholder perspectives on organizational learning, i.e. managers and their subordinates, thereby contributing to the understanding of leader training effects on learning climate from different perspectives.

\section{Method}

\section{Design and Context}

The study was set within a forest industry organization in Sweden with approximately 800 employees. The study used a pre- (November 2011) and post-intervention (March 2013) questionnaire survey. The intervention was agreed with the organization, developed and conducted by its external occupational health service, and evaluated by the research team. The goals of the intervention were aligned with the organization's vision and objectives, and its main outcomes were improvements in transformational leadership behaviors, safety climate, and organizational learning. Evaluation studies reported elsewhere (Tafvelin et al., 2015, von Thiele Schwarz et al., 2015) have demonstrated significant improvements in leader and employees' ratings of transformational leadership behaviors and safety climate as a result of the intervention.

\section{The Intervention}

The intervention was implemented between December 2011 and March 2013. It comprised of a total of 20 days of training in groups of about 20 managers. Multiple training methodologies were used as recommended in prior leadership training literature (Cacioppe, 1998), including feedback on a 360-degree evaluation of participants' leadership to improve self-knowledge, experiential learning, modeling of leadership behaviors, lecturing, and practice of newly learned skills. To allow participants to build relationships with other managers in the 
organization and learn from their experience, the groups consisted of managers from different sections of the organization.

The intervention commenced with individual feedback on the 360-degree evaluation of the participating managers' leadership behaviors. Thereafter, the intervention consisted of two blocks of training: one theoretical and mainly classroom-based, and one practical with exercises and skills-training taking place in the classroom and at the workplace. The practical sessions included additional skills training, for example in feedback and information sharing, the alignment of one's own and one's employees' activities to organizational goals, coordination of activities and transformational leadership behaviors. The theoretical block encompassed 14 days over a period of six months (December 2011 to June 2012). The practical block consisted of a total of six days (August 2012 to March 2013). During the practical block each manager was asked to apply the learning from the theoretical block and work with their work groups to improve an area of their choice (i.e., routine process improvements). For example, one improvement project focused on information-sharing in one of the work stations, including improving collective leadership, collaboration efficiency, and feedback and information-sharing among team members and between line managers and subordinates. The managers worked on their improvement projects between sessions and received feedback and support during the sessions. Thus, the intervention offered the managers opportunities to reflect and acquire skills by working on realizing improvements in the work place. In addition, allowing managers to choose their areas of improvement for the practical exercises offered an opportunity to tailor the training to the work challenges each of the participants experienced. 
To support the leadership training, efforts were made to ensure senior management engagement, alignment between the objectives of the leadership training and organizational objectives and to provide a supporting structure for the line managers. This was achieved via regular meetings between the occupational health service and the senior management team throughout the program. This supplementary component of the intervention was based on the notion that the influence of leadership on organizational learning can be both direct, i.e. through line managers' actions, and more indirect though senior managers' actions to create supporting structures.

\section{Participants}

All line managers $(\mathrm{N}=101)$ in the organization were given the opportunity to participate in the intervention. Line managers were defined as the management level directly above nonmanagerial workers, and in this organization included production managers and section managers with employee supervisory responsibilities. At the pre-intervention all line managers answered the baseline survey $\left(\mathrm{N}_{\text {pre }}=101\right.$; response rate $\left.\mathrm{RR}=100 \%\right)$. The postintervention follow-up questionnaire was administered to all line managers who were employed by the organization at that time (a total of 97 , of whom $\mathrm{N}_{\text {post }}=94$ responded; $\mathrm{RR}=97 \%$ ), and six of them did not give consent for their data to be used in research. Another twelve line mangers were excluded due to missing data on pre- or post-intervention survey. A total of 76 line managers $(\mathrm{RR}=75.2 \%)$ were included in the present study, they had completed the relevant items at both the pre- and post-intervention survey and given informed consent for the data to be used in research. Line managers' age ranged from 30 to 59 years $\left(\mathrm{M}_{\mathrm{age}}=41.2, \mathrm{SD}=8.1\right)$, the gender breakdown was $76.3 \%$ male and $23.7 \%$ female, and they had mean tenure in their current position of 5.5 years $(\mathrm{SD}=5.6)$, and mean tenure in the company was 19.8 years $(\mathrm{SD}=11.2)$. 
The managers were also asked to invite five of their subordinates (both employees they felt close to and employees they perceived as more distant) to complete the employee survey. A total of 290 employees were invited to participate, $\mathrm{N}_{\mathrm{pre}}=212$ ( $\mathrm{RR}=73.1 \%$ ) completed preintervention surveys, and $\mathrm{N}_{\text {post }}=141(\mathrm{RR}=48.6 \%)$ completed the post-intervention survey. A total of 20 employees were excluded due to missing data on the pre- or post-intervention survey or not approving the data to be used in research. The final sample of employees analyzed in the present study consisted of 121 employees $(\mathrm{RR}=41.7 \%)$. Employees' age ranged from 20 to 60 years $\left(\mathrm{M}_{\mathrm{age}}=46.4, \mathrm{SD}=9.3\right)$, and the gender breakdown was $81.1 \%$ male and $18.9 \%$ female. Their tenure in the company ranged from $<1$ to 42 years $(M=22.8$, $\mathrm{SD}=10.5)$, and their tenure in the current position was mean 12.0 years $(\mathrm{SD}=8.0)$.

\section{Procedure}

An introductory letter outlining the aim of the study and a personal link to a web-based questionnaire was emailed to each participant. It was emphasized that participation was voluntary and all respondents were asked to provide written informed consent to participate. Two reminders were sent during the response window of three weeks. The study was approved by the researcher's University ethical review board.

\section{Measures}

Five dimensions of organizational learning were assessed using the short version of the Dimensions of Organizational Learning Questionnaire (DLOQ-A) (Yang et al., 2004, Lien et al., 2006, Joo and Shim, 2010, Marsick and Watkins, 2003). Specifically, the subscales Continuous Learning, Dialogue and Inquiry, Team Learning, Embedded Systems and Empowerment were used. Table 1 presents the items and Cronbach's alpha values for each 
subscale based on the data from the pre-intervention survey. Participants were asked to rate a number of statements about their workplace on a 6-point Likert scale (from $1=$ almost never true to $6=$ almost always true). Following a Swedish validation of the scale (Augustsson et al., 2013), the item "Staff help each other learn" in the in the Continuous learning subscale of the original DLOQ-A was replaced with "Staff can get money and other resources to support their learning". Confirmatory factor analysis has indicated that this subscale has appropriate psychometric properties (Hasson et al., 2013).

\section{Table 1 about here}

In addition, to examine the degree to which the changes between the pre- and postintervention assessment were due to the intervention, an item was added in the postintervention line manager and employee surveys on whether there had been any changes in organizational learning that they could attribute to the leadership training. For the employees, this was formulated as "Have you experienced changes in organizational learning during the last six months as a consequence of the leadership training intervention?", with five response alternatives ("I haven't experienced any changes", "I have experienced changes and these were changes for the better/changes for the worse/changes that didn't affect my work situation/don't know"). For the line managers the corresponding item was "I think that the leadership training intervention has contributed to improvements within organizational learning", also with five response alternatives (“completely untrue", "somewhat untrue", "neither untrue nor true", "somewhat true", "completely true"). 


\section{Results}

Employees' ratings on the single item on perceived changes in organizational learning due to the intervention showed that $42 \%(n=110)$ had not perceived any changes, $22 \%(n=57)$ had perceived changes for the better, $3 \%(n=7)$ had perceived changes for the worse, $13 \%(n=44)$ had perceived changes that did not affect their own work situation, and $16 \%(n=42)$ did not know. Similarly, $14 \%(n=11)$ of line managers answered "completely true", 65\% $(n=51)$ responded "somewhat true", $20 \%(\mathrm{n}=16)$ selected "neither untrue nor true", and 1\% $(\mathrm{n}=1)$ responded "somewhat untrue" on the equivalent item on perceived changes in organizational learning as a result of the training intervention.

The ratings of the five dimensions of organizational learning before and after the intervention were compared using repeated measures ANOVA, separately for line managers and employees. The results are shown in Table 3. Line managers' ratings of the Continuous Learning were significantly higher after the intervention, compared to their pre-intervention ratings. As a result of the intervention, line managers perceived that employees were given time, financial, and other resources to support their learning, and were also rewarded for learning. No other significant changes in line managers' perceptions of organizational learning before and after the intervention were observed. Employees' perceptions of Embedded Systems changed significantly after the intervention. They saw improvements in how the organization takes measures to create infrastructures for learning, such as making lessons learned available and evaluating the results of training. Similarly, employees' ratings of Empowerment also increased after the intervention. They perceived that they received acknowledgement for taking initiatives and calculated risks, as well as a sense of control over resources important for accomplishing their work tasks. The data did not indicate any other significant changes in organizational learning before and after the intervention. 
Table 2 about here

\section{Discussion}

This study aimed to fill an identified gap in the literature by examining the impact of a leadership training intervention on organizational learning. The data showed that both line managers and employees' perceptions of three dimensions of organizational learning improved significantly after the leadership training. Specifically, managers' ratings of Continuous Learning improved significantly, indicating that they perceived that staff in the organization were to a higher degree given time and other resources for learning and were rewarded for learning. Similarly, employees' ratings of Empowerment and Embedded systems also improved after the intervention. These changes indicated that they perceived that efforts to establish systems to capture and share learning and the organization's process to create and share a collective vision and receive feedback from its members about the gap between the current status and the new vision had improved substantially.

Behind these observed changes in perceptions of organizational learning were changes in transformational leadership behaviors, which also increased as a result of the training in this group of line managers (Tafvelin et al., 2015). This study has provided evidence that transformational leadership, which was at the core of the training intervention, is a useful mechanism for understanding the relationship between leader training and organizational learning. Elsewhere, transformational leadership has also been shown to be related to high levels of organizational learning (García-Morales et al., 2012), for instance, by generating greater awareness and acceptance of the organizational goals and fostering a shared vision (Wick and León, 1995). It is possible that in the present study, line managers' more frequently 
enacted transformational leadership behaviors also fostered learning and feedback systems that, in turn, improved organizational learning.

The findings also indicated that during the timeframe for intervention evaluation, line managers and employees perceived that the effects of the training intervention were at different levels of organizational learning. Specifically, the employees experienced improved organizational processes for learning, as indicated by their ratings of Empowerment and Embedded Systems, which correspond to organizational-level learning. They did not perceive any changes in team or individual-level organizational learning. On the other hand, the managers reported that employees were offered more time and other resources for learning and rewards for learning, which is captured by Continuous Learning and indicates changes in employee individual-level learning. They did not perceive changes in organizational- or teamlevel organizational learning. It is possible that, as a direct result of the training intervention, the managers changed their behaviors by offering more opportunities for learning to employees at the individual level. However, employees' did not seem to notice these changes, which is in line with findings that large parts of improvement initiatives reported by managers are not noticed by their subordinates (Hasson et al., 2012). However, employees did perceive changes at the broader organizational level. It is unclear whether these differences highlight the specific aspects of organizational learning that are important for different groups of stakeholders, or whether they merely indicate actual exposure levels to the intervention and its consequences. Indeed, at the core of organizational learning theory is the idea that learning occurs at all levels, from the individual to the group and the organization (Crossan et al., 1995, Crossan et al., 1999, Marsick and Watkins, 2003). Developing organizational learning requires strength at all these levels (Marsick and Watkins, 2003). The results of the present study pose the question whether all groups of stakeholders need to perceive improvement at 
all levels, or whether it is enough that change occurs at different levels as a sum of the stakeholders' perceptions.

The data also showed that perceptions of three dimensions of organizational learning did not change over time, rendering any inferences on the mechanisms for the effects of the intervention tentative. Previous studies have shown that baseline conditions have an impact on whether organizations can make the most of an intervention (Augustsson et al., 2014, Ulhassan et al., 2014). Organizations with good work processes, leadership, and climate at pre-intervention may be in a better position to benefit from interventions and see improvements over time (Augustsson et al., 2014, Ulhassan et al., 2014). It has also been argued that a better organizational learning climate is required to take advantage of improvement or change initiatives (Westerberg, 2004). In the current study, the preintervention mean values for all five dimensions of organizational learning and for both line managers and employees were lower than those reported in other studies (Marsick and Watkins, 2003). For instance, employees' mean rating of Continuous Learning at baseline was 2.96 (range from 1 to 6), while previous studies have reported mean values between 3.94 and 4.26 for employees (Augustsson et al., 2013, Hernandez, 2003). There is a possibility that in the present organization the baseline perceptions of organizational learning were so poor that they hindered developments in organizational learning. Of course, this interpretation is made on the proviso that the norms on organizational learning can be compared across types of work and industries and in light of the proposition that better baseline conditions are important for change initiatives (Westerberg, 2004).

\section{Implications for research and practice}

The present findings offer important implications for developing and evaluating leadership 
training programs and for research into organizational learning and leadership more broadly.

One implication for future practice and research would be to focus on the individual contributions of the different components of the training program. Because the current intervention consisted of a multiple component program, it was not possible to separate the different components and to draw conclusions on the effects of each of these components. For example, it would be interesting to separate the role of meetings with senior management on line managers' ratings of organizational learning. Support comes from evidence on the importance of senior management for achieving change in practice (Cacioppe, 1998). Past evaluation study have shown increases in transformational leadership behaviors among the managers who took part in this program (Tafvelin et al., 2015). Therefore, a recommendation for practice would be that both components (i.e., transformational leadership and senior management support), should be included in leadership training aiming to improve organizational learning. A recommendation for research would be to focus on improving our understanding of how different components of leadership training impact different dimensions of organizational learning. Related to this, the fact that neither the employees nor the line managers in the present study experienced improvements in team-level learning (i.e., the teams' freedom to adapt goals and ability to adapt their thinking as a result of new learning) indicates that other types of activities may be needed to improve team learning. It is possible that an optimally tailored training program would include a combination of leader training and team level activities in order to have impact on organizational learning at this level.

The finding that managers and employees had differential perceptions of what aspects of organizational learning changed as a result of the leadership training implies that an evaluation of both stakeholders' perceptions may provide a more comprehensive approach to 
developing organizational learning. As mentioned, do all groups of stakeholders need to perceive improvement at all levels or can change be assessed as a sum of the stakeholders' perceptions? Therefore, evaluations of leadership training programs should examine changes in organizational learning from several stakeholders. In addition, the design and evaluation of leadership training should take into consideration the baseline values for the target outcomes before starting the intervention. If baseline values are low, it may be necessary to first attend to the work processes, leadership, and group climate in order to improve the conditions to benefit from the intervention. It is also important to replicate the findings in multiple organizations and sectors.

The study also highlights the complexity of selecting the most appropriate time points to evaluate an intervention. It is possible that improvements in the different aspects of organizational learning occur at different rates. Training transfer is a lengthy process and perhaps a second or even a third follow-up survey would have revealed changes in the remaining dimensions of organizational learning. This is also in line with recent discussion on measuring effects of an intervention at time points that are theoretically justified for the effects to occur (von Thiele Schwarz and Hasson, 2013). For instance, the items measuring Dialogue and Inquiry cover general perceptions rather than specific behaviors or changes; the latter are more likely to be a direct outcome of the intervention. It is possible that the general climate did not change between the two assessments, since climate and culture take time to change. A lack of change in participants' ratings of this dimension may indicate that more time might be needed for the training to impact on culture. On the other hand, the intervention was longer than most training programs (Cole, 2008), stretching over a period of 16 months. Conversely, there is also a possibility that some of the more immediate effects of the training program on organizational learning had already diminished at post-measurement, due to the 
lengthy intervention period. Future studies should examine how the different aspects of organizational learning change through time after a leadership training program.

\section{Limitations}

The results ought to be interpreted with caution as the study has a number of potential limitations. First, because the data used in the study came from a single industrial company and no control conditions were available, it is not possible to separate the effects of time from intervention effects. However, no other learning initiatives were implemented in the organization during the study period. Furthermore, self-report was used to measure organizational learning. Although this allowed to assess individual perceptions, which are not easily measured through more objective measures (Hurrell et al., 1998), self-report also has disadvantages, such as social desirability and negative affectivity (Hurrell et al., 1998). When all variables are measured using self-report these issues are pronounced, potentially leading to spurious relationships (Hurrell et al., 1998).

Additionally, two of the DLOQ-A dimensions, System Connections and Providing Leadership for Learning, were not included in the intervention survey. The former taps into how people and the organization are linked to its broader environment, which was not a primary goal of the leadership training program. The latter, providing leadership for learning, was one of the intervention target areas, but the participating organization asked to reduce the number of items in the survey directly concerning leadership. It is a common need in organizational research to adapt an evaluation to the needs of the organization (Kristensen, 2005). Moreover, the inclusion in the post-intervention survey of a one-item measure of participants' perceptions of changes in organizational learning as a consequence of the leadership training could potentially limit the interpretation of the findings. However, it does add information 
about whether any changes in pre- and post-intervention assessment were perceived to be related to the intervention. This additional information is particularly useful when the design does not allow to separate between the effects time and of the intervention.

In addition, the fact that the procedure involved the line managers selecting subordinates to complete the survey meant that not all employees were included. Although this is a commonly used strategy in leadership research (Fleenor et al., 2010), it is unclear whether it can affect the ratings of organizational learning. The line managers were asked to invite employees they felt close to as well as employees they felt more distant to, which would indicate that the sample is representative of the population of employees. To balance this potential limitation, a strength of the study is the large sample size for both line managers and employees.

Finally, since there is a lack of relevant studies, it is unclear how long the effects on organizational learning can be expected to occur after the leadership training. As stated above, it is possible that measuring the outcomes 16 months after pre-measurement is too long a time lapse to detect effects of a change, or that measuring it directly after the intervention ends is too soon to capture how employees perceive the possible effects on organizational learning. It is also possible that the links of effects may be longer and more indirect than was possible to evaluate in the current study. Several follow-up measurements and more detailed information about the intervention processes at different work units, i.e. a process evaluation, would be needed. 


\section{Conclusions}

This intervention study has provided evidence on the importance of leadership training for organizational learning. Line managers and employees' ratings of three dimensions of organizational learning improved substantially after the leadership training intervention. Furthermore, the fact that line managers perceived changes in dimensions of individual-level learning, whereas employees perceived changes in dimensions of organization-level learning, implies that leadership training can affect different levels of learning for different stakeholder groups. It is important to further examine the mechanisms by which leadership training can improve organizational learning at all levels and for all groups of employees. This study provides needed knowledge on the activities to be included in leadership development programs when organizational learning is a target outcome of that. This study also highlighted ways to evaluate this type of intervention.

\section{References}

AMITAY, M., POPPER, M. \& LIPSHITZ, R. 2005. Leadership styles and organizational learning in community clinics. Learning Organization, The, 12, 57-70.

ARAGON-CORREA, J. A., GARCÍA-MORALES, V. J. \& CORDÓN-POZO, E. 2007. Leadership and organizational learning's role on innovation and performance: lessons from Spain. Industrial marketing management, 36, 349-359.

ARGOTE, L. 2011. Organizational learning research: Past, present and future. Management Learning, 42, 439-446.

ARGYRIS, C. \& SCHON, D. A. 1996. Organizational Learning 11: Theory, method and practice. Reading MA: Addison-Wellesley.

AUGUSTSSON, H., TÖRNQUIST, A. \& HASSON, H. 2013. How can effects of a workplace learning intervention be understood? Journal of Health Organization and Management, 27.

AUGUSTSSON, H., VON THIELE, S., U, STENFORS-HAYES, T. \& HASSON, H. 2014. Investigating Variations in Implementation Fidelity of an Organizational-Level Occupational Health Intervention. International journal of behavioral medicine.

AVOLIO, B. J., REICHARD, R. J., HANNAH, S. T., WALUMBWA, F. O. \& CHAN, A. 2009. A meta-analytic review of leadership impact research: Experimental and quasiexperimental studies. The Leadership Quarterly, 20, 764-784.

BAKER, W. E. \& SINKULA, J. M. 2002. Market orientation, learning orientation and product innovation: delving into the organization's black box. Journal of marketfocused management, 5, 5-23. 
BARLING, J., WEBER, T. \& KELLOWAY, E. K. 1996. Effects of transformational leadership training on attitudinal and financial outcomes: A field experiment. Journal of applied psychology, 81, 827.

BASS, B. M. 1985. Leadership and performance beyond expectations, Free Press; Collier Macmillan.

BASS, B. M. 1999. Two decades of research and development in transformational leadership. European journal of work and organizational psychology, 8, 9-32.

BASS, B. M. \& RIGGIO, R. E. 2006. Transformational leadership, Psychology Press.

BEATTIE, R. S. 2006. Line managers and workplace learning: Learning from the voluntary sector. Human Resource Development International, 9, 99-119.

BERSON, Y., NEMANICH, L. A., WALDMAN, D. A., GALVIN, B. M. \& KELLER, R. T. 2006. Leadership and organizational learning: A multiple levels perspective. The Leadership Quarterly, 17, 577-594.

BROWN, W. \& MAY, D. 2012. Organizational change and development: The efficacy of transformational leadership training. Journal of Management Development, 31, 520536.

CACIOPPE, R. 1998. An integrated model and approach for the design of effective leadership development programs. Leadership \& Organization Development Journal, 19, 44-53.

COAD, A. F. \& BERRY, A. J. 1998. Transformational leadership and learning orientation. Leadership \& Organization Development Journal, 19, 164-172.

COLE, N. 2008. How long should a training program be? A field study of "rules-of-thumb". Journal of Workplace Learning, 20, 54-70.

CROSSAN, M. M., LANE, H. W. \& WHITE, R. E. 1999. An organizational learning framework: from intuition to institution. Academy of management review, 24, 522537.

CROSSAN, M. M., LANE, H. W., WHITE, R. E. \& DJURFELDT, L. 1995. Organizational learning: Dimensions for a theory. International Journal of Organizational Analysis, 3, 337-360.

DAVIS, D. \& DALEY, B. J. 2008. The learning organization and its dimensions as key factors in firms' performance. Human Resource Development International, 11, 51-66.

DUYGULU, S. \& KUBLAY, G. 2011. Transformational leadership training programme for charge nurses. Journal of advanced nursing, 67, 633-642.

DVIR, T., EDEN, D., AVOLIO, B. J. \& SHAMIR, B. 2002. Impact of transformational leadership on follower development and performance: A field experiment. Academy of management journal, 45, 735-744.

ELLINGER, A. D., ELLINGER, A. E., YANG, B. \& HOWTON, S. W. 2002. The relationship between the learning organization concept and firms' financial performance: An empirical assessment. Human Resource Development Quarterly, 13, $5-22$.

ELLINGER, A. D., ELLINGER, A. E., YANG, B. \& HOWTON, S. W. 2003. Making the business case for the learning organization concept. Advances in Developing Human Resources, 5, 163-172.

FITZGERALD, S. \& SCHUTTE, N. S. 2010. Increasing transformational leadership through enhancing self-efficacy. Journal of Management Development, 29, 495-505.

FLEENOR, J. W., SMITHER, J. W., ATWATER, L. E., BRADDY, P. W. \& STURM, R. E. 2010. Self-other rating agreement in leadership: A review. The Leadership Quarterly, $21,1005-1034$.

GARCÍA-MORALES, V. J., JIMÉNEZ-BARRIONUEVO, M. M. \& GUTIÉRREZGUTIÉRREZ, L. 2012. Transformational leadership influence on organizational 
performance through organizational learning and innovation. Journal of Business Research, 65, 1040-1050.

GOMEZ, C. \& RANFT, A. L. 2003. The inf luence of organizational variables on the transferability of management practices: An examination of traditional and learning manufacturing environments in Mexico. Journal of Business Research, 6, 989-997.

HANNAH, S. T. \& LESTER, P. B. 2009. A multilevel approach to building and leading learning organizations. The Leadership Quarterly, 20, 34-48.

HARDY, L., ARTHUR, C. A., JONES, G., SHARIFF, A., MUNNOCH, K., ISAACS, I. \& ALLSOPP, A. J. 2010. The relationship between transformational leadership behaviors, psychological, and training outcomes in elite military recruits. The Leadership Quarterly, 21, 20-32.

HASSON, H., GILBERT-OUIMET, M., BARIL-GINGRAS, G., BRISSON, C., VÉZINA, M., BOURBONNAIS, R. \& MONTREUIL, S. 2012. Implementation of an organizational-level intervention on the psychosocial environment of workcomparison of managers' and employees' views. Journal of Occupational and Environmental Medicine, 54.

HASSON, H., TAFVELIN, S. \& VON THIELE SCHWARZ, U. 2013. Comparing Employees and Managers' Perceptions of Organizational Learning, Health, and Work Performance. Advances in Developing Human Resources, 15, 163-176.

HERNANDEZ, M. 2003. Assessing tacit knowledge transfer and dimensions of a learning environment in Colombian businesses. Advances in Developing Human Resources, 5 , 215-221.

HUBER, G. P. 1991. Organizational Learning: The Contributing Processes and the Literatures. Organization Science, 2, 88-115.

HURRELL, J. J., NELSON, D. L. \& SIMMONS, B. L. 1998. Measuring job stressors and strains: Where we have been, where we are, and where we need to go. Journal of Occupational Health Psychology, 3, 368-389.

JIMÉNEZ-JIMÉNEZ, D. \& SANZ-VALLE, R. 2011. Innovation, organizational learning, and performance. Journal of Business Research, 64, 408-417.

JOO, B.-K. \& SHIM, J. H. 2010. Psychological empowerment and organizational commitment: the moderating effect of organizational learning culture. Human Resource Development International, 13, 425-441.

KELLOWAY, E. K., BARLING, J. \& HELLEUR, J. 2000. Enhancing transformational leadership: the roles of training and feedback. Leadership \& Organization Development Journal, 21, 145-149.

KRISTENSEN, T. S. 2005. Intervention studies in occupational epidemiology. Occup Environ Med, 62, 205-10.

LIEN, B. Y. H., HUNG, R. Y. Y., YANG, B. \& LI, M. 2006. Is the learning organization a valid concept in the Taiwanese context? International Journal of Manpower, 27, 189203.

MARSICK, V. J. \& WATKINS, K. E. 2003. Demonstrating the value of an organization's learning culture: The dimensions of the learning organization questionnaire. Advances in Developing Human Resources, 5, 132-151.

NONAKA, I. \& TAKEUCHI, H. 1995. The knowledge-creating company: How Japanese companies create the dynamics of innovation, Oxford University Press, USA.

SANTOS-VIJANDE, M. L., LÓPEZ-SÁNCHEZ, J. Á. \& TRESPALACIOS, J. A. 2012. How organizational learning affects a firm's flexibility, competitive strategy, and performance. Journal of Business Research, 65, 1079-1089.

SCHEIN, E. H. 2004. Organizational culture and leadership, Jossey-Bass. 
TAFVELIN, S., HASSON, H., HOLMSTRÖM, S. \& VON THIELE SCHWARZ, U. 2015. Leadership training of formal and informal leaders: a 360 perspective. manuscript.

ULHASSAN, W., WESTERLUND, H., THOR, J., SANDAHL, C. \& VON THIELE SCHWARZ, U. 2014. Does Lean implementation interact with group functioning? . Journal of Health Organization and Management, 28, 196-213.

VALENCIA, J. C. N., VALLE, R. S. \& JIMÉNEZ, D. J. 2010. Organizational culture as determinant of product innovation. European Journal of Innovation Management, 13, 466-480.

VERA, D. \& CROSSAN, M. 2004. Strategic leadership and organizational learning. Academy of management review, 29, 222-240.

VON THIELE SCHWARZ, U. \& HASSON, H. (eds.) 2013. Alignment for Achieving a Healthy Organization: Springer.

VON THIELE SCHWARZ, U., HASSON, H. \& TAFVELIN, S. 2015. Leadership training improves managerial safety self-efficacy and employee safety climate. Safety Science, In Press.

WESTERBERG, K. 2004. Workplace development and learning in elder care-the importance of a fertile soil and the trouble of project implementation. Outlines. Critical Practice Studies, 6, 61.

WICK, C. W. \& LEÓN, L. S. 1995. From ideas to action: Creating a learning organization. Human Resource Management, 34, 299-311.

YANG, B. 2003. Identifying valid and reliable measures for dimensions of a learning culture. Advances in Developing Human Resources, 5, 152-162.

YANG, B., WATKINS, K. E. \& MARSICK, V. J. 2004. The construct of the learning organization: Dimensions, measurement, and validation. Human Resource Development Quarterly, 15, 31-55.

YUKL, G. 2009. Leading organizational learning: Reflections on theory and research. The Leadership Quarterly, 20, 49-53.

YUKL, G. \& LEPSINGER, R. 2004. Flexible leadership, UK. 
Table 1. The reliability indices (Cronbach's alpha in parenthesis) and items of the five subscales of the short version of the Dimension of Learning Organization Questionnaire (DLOQ-A) used in the study

\begin{tabular}{ll}
\hline Dimension & In my organization... \\
\hline Individual level: & staff can get money and other resources to support their learning. \\
Continuous learning & staff are given time to support learning. \\
\begin{tabular}{ll} 
(.76) & staff are rewarded for learning. \\
\hline Individual level: & staff give open and honest feedback to each other. \\
Dialogue and & whenever staff state their view, they also ask what others think. \\
inquiry (.64) & staff spend time building trust with each other. \\
\hline Group level: Team & teams have the freedom to adapt their goals as needed. \\
learning & teams revise their thinking as a result of group discussions or \\
(.68) & information collected. \\
& teams are confident that the organization will act on their \\
& recommendations.
\end{tabular}
\end{tabular}

Organization level: The organization recognizes staff for taking initiative.

Empowerment (.74) The organization gives staff control over the resources they need to accomplish their work.

The organization supports staff who take calculated risks.

Organization level: the organization creates systems to measure gaps between current and Embedded systems expected performance. the organization makes its lessons learned available to all staff. the organization measures the results of the time and resources spent on training. 

Table 2. Means, standard deviation, and summary of repeated measures ANOVA results for line managers and employees

\begin{tabular}{|c|c|c|c|c|c|c|c|c|c|}
\hline & \multicolumn{5}{|c|}{ Line managers } & \multicolumn{4}{|c|}{ Employees } \\
\hline & Time & Mean & $\mathrm{SD}$ & F-value & p-value & Mean & $\mathrm{SD}$ & F-value & p-value \\
\hline \multirow[t]{2}{*}{ Continuous learning } & 1 & 3.38 & 0.93 & 9.39 & $.00 * *$ & 2.99 & 1.14 & 1.31 & .26 \\
\hline & 2 & 3.71 & 0.98 & & & 3.11 & 1.19 & & \\
\hline \multirow[t]{2}{*}{ Dialogue and inquiry } & 1 & 3.16 & 0.83 & 0.12 & .73 & 3.42 & 0.93 & 0.00 & .95 \\
\hline & 2 & 3.18 & 0.82 & & & 3.43 & 1.13 & & \\
\hline \multirow[t]{2}{*}{ Team learning } & 1 & 3.27 & 0.75 & 0.25 & .62 & 3.34 & 1.00 & 0.04 & .85 \\
\hline & 2 & 3.22 & 0.87 & & & 3.32 & 1.11 & & \\
\hline \multirow[t]{2}{*}{ Embedded systems } & 1 & 3.16 & 0.93 & 0.18 & .67 & 2.90 & 1.04 & 12.72 & $.00 * * *$ \\
\hline & 2 & 3.22 & 1.03 & & & 3.22 & 0.96 & & \\
\hline \multirow[t]{2}{*}{ Empowerment } & 1 & 3.44 & 0.77 & 0.39 & .53 & 2.89 & 1.04 & 6.57 & $.01 * *$ \\
\hline & 2 & 3.38 & 0.85 & & & 3.14 & 1.04 & & \\
\hline
\end{tabular}

Notes. Line managers $\mathrm{n}=76$, employees $\mathrm{n}=121 ; 1=$ pre-intervention survey, $2=$ post-intervention survey; $* \mathrm{p}<.05, * * \mathrm{p}<.01, * * * \mathrm{p}<.001$. 